\title{
Carrier-Mediated $\beta$-D-Hydroxybutyrate Transport in Brush-Border Membrane Vesicles from Rat Placenta
}

\author{
SARA R. ALONSO DE LA TORRE, MARÍA A. SERRANO, AND JOSÉ M. MEDINA \\ Departamento de Bioquimica y Biologia Molecular, Facultad de Farmacia, Universidad de Salamanca, \\ Salamanca, Spain
}

\begin{abstract}
Carrier-mediated $\beta$-D-hydroxybutyrate transport in brush-border membrane (maternal-sided) vesicles prepared from trophoblast rat placenta was studied. The existence of a carrier-mediated transport system for $\beta$-D-hydroxybutyrate in brush-border membrane vesicles was substantiated by the strong inhibitory effect of the protein modifier p-chloromercuriphenyl sulfonic acid and by the saturability of $\beta$-D-hydroxybutyrate uptake as a function of $\beta$-D-hydroxybutyrate concentration. $\beta$-D-hydroxybutyrate uptake was stimulated by the presence of an inward-directed proton gradient but not by an inwarddirected $\mathrm{Na}^{+}$gradient. The mechanism for transport of $\beta$ D-hydroxybutyrate seems to be a $\beta$-D-hydroxybutyrate $/ \mathrm{H}^{+}$ symport and not a $\beta$-D-hydroxybutyrate $/ \mathrm{OH}^{-}$antiport because $\beta$-D-hydroxybutyrate transport was not sensitive to 4,4-diisothiocyano-2,2'-stilbenedisulfonic acid or furosemide. The $\mathrm{Km}, \mathrm{V}_{\max }$, and $\mathbf{k}_{\mathrm{d}}$ calculated by applying the iteration procedure to the data were $16 \mathrm{mM}, 58 \mathrm{nmol}$. $\mathrm{mg}^{-1} \cdot 10 \mathrm{~s}^{-1}$, and $0 \mathrm{~nL} \cdot \mathrm{mg}^{-1} \cdot \mathrm{s}^{-1}$, respectively. The $\beta$-Dhydroxybutyrate transport system might be shared by other monocarboxylic acids, and the carrier shows reversibility and exchange properties. There were no significant changes in the kinetic parameters of the $\beta$-D-hydroxybutyrate transport system during the last $3 \mathrm{~d}$ of gestation. Nevertheless, there was a significant increase in the capacity of the $\beta$-D-hydroxybutyrate transport system in brushborder membrane vesicles prepared from fasted pregnant rats, suggesting that the rise in maternal ketone body levels occurring as a consequence of maternal starvation is concurrent with the stimulation of the activity of the $\beta$-Dhydroxybutyrate placental carrier to supply the fetus with ketone bodies. The signal mediating the stimulation of carrier activity due to starvation remains to be elucidated. (Pediatr Res 32: 317-323, 1992)
\end{abstract}

\section{Abbreviations}

BBMV, brush-border membrane vesicles

Tris, 2-amino-2-hydroxymethylpropane-1,3-diol

Mes, 2-(N-morpholino)-ethanesulfonic acid

p-CMBS, p-chloromercuriphenylsulfonic acid

FCCP, carbonylcyanide p-trifluoromethoxyphenylhydrazone

DIDS, 4,4' -diisothiocyano-2,2' -stilbenedisulfonic acid

$\mathrm{SH}$, sulfhydril

pHin, intravesicular $\mathbf{p H}$

pHout, extravesicular pH

Received August 1, 1991; accepted May 4, 1992

Correspondence: J. M. Medina, Departmento de Bioquimica y Biologia Molecular, Facultad de Farmacia Apartado 449, E-37080 Salamanca, Spain.

Supported in part by a grant from CICYT, Spain. S.R. Alonso de la Torre is the recipient of a fellowship from the Fondo de Investigaciones Sanitarias de la Seguridad Social (FISSS), Spain.
Ketone bodies are used by both the placenta and the fetus for the synthesis of lipids and as a source of energy (1-3). However, ketone bodies are synthesized by maternal liver because ketogenesis is not active in fetal liver during gestation (4). The levels of circulating fatty acids increase in maternal blood during late gestation, this being associated with high concentrations of ketone bodies in maternal and fetal blood. Thus, fatty acids are converted into ketone bodies in the maternal liver, from which they are transferred to the fetus across the placenta. Once in the fetus, ketone bodies can be transformed into lipids or amino acids (3) or oxidized to $\mathrm{CO}_{2}$ for energy production (1). Moreover, ketone bodies seem to be preferred to other relevant substrates because high levels of $\beta$-D-hydroxybutyrate may inhibit the oxidation of glucose or lactate in the fetal brain (3-7).

The concentrations of ketone bodies in the mother and fetus are related, there being a concentration gradient from the mother to the fetus that may induce transference in that sense $(1,8)$. Because $\beta$-D-hydroxybutyrate has an ionization constant of 4.4 , it is negatively charged at physiologic $\mathrm{pH}$, thereby hindering its diffusion across the membrane. Consequently, the occurrence of a specific transporter for $\beta$-D-hydroxybutyrate would allow the supply of this substrate at rates far higher than those foreseen for simple diffusion. Mediated transfer mechanisms for ketone bodies in liver, kidney, erythrocytes, thymocytes, and blood-brain barrier have been described (9-12). The existence of a mediated transfer mechanism for ketone bodies across the placenta may be especially relevant in situations such as maternal fasting, the ingestion of fat-rich diets, or uncontrolled diabetes. Under these circumstances, the maternal plasma concentrations of ketone bodies are highly increased, resulting in a parallel increase in the fetal concentration of ketone bodies (13).

The aim of the present study was to determine the existence of a specific transport mechanism for $\beta$-D-hydroxybutyrate in rat placenta BBMV. The effect of gestational age and maternal fasting on the kinetic parameters of $\beta$-D-hydroxybutyrate were also examined.

\section{MATERIAL AND METHODS}

Reagents. $\beta$-D- $\left[3-{ }^{14} \mathrm{C}\right]$-hydroxybutyric acid was purchased from New England Nuclear (Itisa, Madrid, Spain). $\beta$-D- and $\beta$-Lhydroxybutyric acid were purchased from Serva (Heidelberg, Germany). L-Lactic acid, pyruvate, phenylmethylsulfonylfluoride, and BSA (Fraction V) were purchased from Sigma Chemical Co. (St. Louis, MO). FCCR was obtained from Aldrich (Steinheim, Germany). All other reagents were of analytical grade.

Preparation of microvillous membranes. Microvillous membranes from rat placenta were prepared by the method of Alonso de la Torre et al. (14), essentially based on that reported by Smith et al. (15) but modified by including two steps involving precipitation of the vesicles with $\mathrm{MgCl}_{2}$. Briefly, the procedure was as follows. Albino Wistar rats, of known gestational age (19.5, 20.5, 
and $21.5 \mathrm{~d}$ ) fed on stock laboratory diet (carbohydrate $58.7 \%$, protein $17.0 \%$, fat $3.0 \%$, and added salts and vitamins) were used for the experiments. Females with a mean weight of $250 \mathrm{~g}$ were caged with males overnight, and conception was confirmed the following morning by the presence of spermatozoa in vaginal smears. Pregnant rats were killed by cervical dislocation, the fetal-placental units were removed, and the fetuses were weighed as further control of gestational age. Each placenta was perfused with cold, low-calcium Krebs-Henseleit buffer ( $\mathrm{pH} 7.4)(16)$ until the placenta appeared free of blood. All subsequent steps were then carried out at $4^{\circ} \mathrm{C}$. The maternal layer of each placenta was peeled off and the remaining labyrinthine tissue was washed once in cold Krebs-Henseleit buffer ( $\mathrm{pH} 7.4)$. The placentas were rinsed three times with $100 \mathrm{mM}$ calcium chloride solution, weighed, and used immediately. The tissue was minced in buffer A $(500 \mathrm{mM}$ sorbitol, $1 \mathrm{mM}$ EGTA, $0.1 \mathrm{mM}$ phenylmethylsulfonylfluoride, and $20 \mathrm{mM}$ Tris/Mes; $\mathrm{pH} 7.4$ ) and homogenized by applying 10 up-down strokes of a motor-driven Teflon glass homogenizer (S-778; B. Braun, Melsungen, Germany). The homogenate was then made up to 10 times the tissue weight with additional buffer $\mathrm{A} . \mathrm{MgCl}_{2}$ was added to a final concentration of $10 \mathrm{mM}$, and after $30 \mathrm{~min}$ standing the homogenate was centrifuged at $800 \times g$ for 10 min using a Beckman L8-M centrifuge (Beckman Instruments España, Madrid, Spain). This yielded a pellet (P1) and a supernatant (S1). P1 was washed with five times the weight of the placenta with buffer $A$ and homogenized with eight up-down strokes of the motor-driven Teflon homogenizer. After addition of $\mathrm{MgCl}_{2}$ to a final concentration of $10 \mathrm{mM}$, the suspension was allowed to stand for $15 \mathrm{~min}$. The washed P1 was centrifuged at $800 \times g$ for $10 \mathrm{~min}$, resulting in another pellet, which was discarded, and a supernatant $\left(\mathrm{S1}^{\prime}\right)$. Supernatants $\mathrm{S} 1$ and $\mathrm{Sl}^{\prime}$ were pooled together and centrifuged at $10400 \times g$ for $20 \mathrm{~min}$. The resulting pellet (P2) was discarded, and the supernatant (S2) was centrifuged at $110000 \times g$ for 45 min using a Beckman L8-M ultracentrifuge. The final supernatant (S3) was discarded, and the cream-colored pellet (P3) was resuspended in a small volume of buffer B ( $500 \mathrm{mM}$ sorbitol and $20 \mathrm{mM}$ Tris/ Mes; pH 7.4) and homogenized six times through a 25-gauge hypodermic needle. The BBMV preparation from rat placenta showed a degree of alkaline phosphatase enrichment seven times greater than that of the placental tissue homogenate. A similar method has been recently reported by Glazier et al. (17), although apparently a better purification was reached as judged by the higher enrichment in alkaline phosphatase observed in their preparations.

Membrane integrity of our BBMV was sustained by the constancy of the apparent intravesicular space for $\beta-\mathrm{D}-\left[3-{ }^{14} \mathrm{C}\right]-\mathrm{hy}-$ droxybutyric acid in vesicle batches $(1.34 \pm 0.13 \mu \mathrm{L} / \mathrm{mg} ; n=$ 20). Alkaline phosphatase activity was similar in intact or Triton $\mathrm{X}$-100-disrupted preparations, suggesting that our vesicles are right-side-out oriented.

Rat membrane vesicles were adjusted to about $15 \mathrm{mg}$ of protein $/ \mathrm{mL}$ and stored in liquid nitrogen until use. To obtain vesicles preloaded with certain ions or substrates, two distinct procedures were used with similar results, namely, entrapment during vesicle formation or application of two cycles of freezing and thawing in the presence of the desired solution.

Enzyme assays. The microvillous membrane vesicle preparation was tested for enrichment in apical plasma membrane and for contamination by basal plasma membrane by analyzing the activity of the following marker enzymes: alkaline phosphatase (EC 3.13.1) (18) and $\mathrm{Na}^{+}-\mathrm{K}^{+}$ATPase (EC 3.6.1.37) (19). $\mathrm{Na}^{+}-$ $\mathrm{K}^{+}$ATPase activity was determined on the day that the membrane fractions were prepared. The degrees of enrichment of the markers were 6 and 0.5 , respectively. Alkaline phosphatase determination was carried out after shortage at $-80^{\circ} \mathrm{C}$. Protein concentration was measured by a modification of the Lowry procedure (20) with serum albumin as standard.

Uptake assays. $\beta$-D- $\left[3-{ }^{14} \mathrm{C}\right]$-hydroxybutyric acid uptake by microvillous membrane vesicles was determined using a rapid filtration technique as described by Hopfer et al. (21). For most experiments, incubations at $37^{\circ} \mathrm{C}$ were started by mixing $10 \mu \mathrm{L}$ of the vesicle preparation in buffer B with $90 \mu \mathrm{L}$ of buffer $\mathrm{B}$ with ${ }^{14} \mathrm{C}$ labeled $\beta$-D-hydroxybutyrate adjusted to $\mathrm{pH} 6.0$ to 7.4 . All experiments were performed with the same inward-directed net osmotic gradient (500/600 in/out). Incubations were stopped with $4 \mathrm{~mL}$ of ice-cold stop solution containing $20 \mathrm{mM}$ Tris-Mes buffer, $350 \mathrm{mM} \mathrm{KCl}$, and $25 \mathrm{mM} \mathrm{MgSO}_{4}$. The diluted samples were rapidly filtered under a negative pressure through wetted cellulose-nitrate filters $(0.65-\mu \mathrm{m}$ pore; Millipore Ibérica, Madrid, Spain), which were then rinsed four times with $4 \mathrm{~mL}$ of stop solution. The entire procedure lasted less than $15 \mathrm{~s}$. Appropriate blanks were made to correct for nonspecific marker retention on the filters. After dissolving the filters in $4 \mathrm{~mL}$ of scintillation fluid (Ready Safe, Beckman), radioactivity was measured in a scintillation spectrophotometer. Uptake buffers were prepared at different $\mathrm{pH}$ values by adding Tris or Mes but keeping the sum of Tris and Mes concentrations equal to $20 \mathrm{mM}$. The exact composition of the uptake buffers and preloading buffers is specified in the figure legends and table footnotes.

Fitting of transport results to Michaelis-Menten equation. Absolute velocity data as a function of the substrate concentration were fitted by iteration to a complex equation involving the sum of one nonsaturable and one saturable component $(22,23)$. The iteration method allows the estimation of $V_{\max }$ and $\mathrm{Km}$ and avoids the error subsequent to working at very high substrate concentrations.

Expression of results. Results are expressed as either absolute uptakes $\left(\mathrm{nmol} \cdot \mathrm{mg}^{-1}\right.$ of protein), absolute velocities $\left(\mathrm{nmol} \cdot \mathrm{s}^{-1}\right.$. $\mathrm{mg}$ of protein $\left.{ }^{-1}\right)$ or relative velocities $\left(\mathrm{nL} \cdot \mathrm{s}^{-1} \cdot \mathrm{mg}\right.$ of protein $\left.{ }^{-1}\right)$ (24). Data are presented as the means $( \pm S E M)$ from several experiments performed with at least two different membrane preparations. Occasionally, representative results obtained with single membrane preparation are shown. The uptake experiments were routinely done in triplicate.

Statistical analyses. Statistical analyses were carried out with $t$ test. Saturation curves were solved by applying nonlinear regression analysis that includes an $F$ test (22). All the calculations were performed with an Apple Macintosh SE microcomputer.

\section{RESULTS}

Effect of $p-C M B S$ on $\beta$-D-hydroxybutyrate uptake. The existence of a carrier-mediated protein with $\mathrm{SH}$ functional groups involved in monocarboxylic acid transport across different epithelia has been deduced from the inhibitory effect of specific modifiers of $\mathrm{SH}$ groups of proteins (25-28). One $\mathrm{mM} \beta$-Dhydroxybutyrate uptake in BBMV preincubated for $45 \mathrm{~min}$ at $25^{\circ} \mathrm{C}$ with $0.55 \mathrm{mM}$ p-CMBS, a nonpermeable organomercurial mercapeptide bond reagent (29), decreased by approximately $50 \%$ as compared with control values $(2.1 \pm 0.15$ versus $5.2 \pm$ $0.14 \mathrm{nmol} \cdot \mathrm{mg}^{-1} \cdot 10 \mathrm{~s}^{-1}$ in controls). The specific inhibitory action of $\mathrm{p}$-CMBS on $\beta$-D-hydroxybutyrate uptake is substantiated by the fact that the sole presence of $0.55 \mathrm{mM}$ p-CMBS without preincubation did not modify the $\beta$-D-hydroxybutyrate uptake level as compared with controls. These results suggest the involvement of SH groups of a protein in $\beta$-D-hydroxybutyrate uptake across BBMV from trophoblast rat placenta.

Effect of extravesicular $p H$ on $\beta$-D-hydroxybutyrate uptake. The effect of variations in extravesicular $\mathrm{pH}$ on the transport of $1 \mathrm{mM} \beta$-D-hydroxybutyrate in BBMV from trophoblast rat placenta is shown in Figure 1. In these experiments extravesicular $\mathrm{pH}$ ranged from 5.2 to 8.2 and the intravesicular $\mathrm{pH}$ was constant and fixed at 7.4. The results show that acidification of the incubation medium induces a significant increase in the $\beta$-Dhydroxybutyrate uptake rate (Fig. 1), suggesting that $\beta$-D-hydroxybutyrate uptake in BBMV is presumably driven by a coupled proton gradient.

Effect of inward-directed $H^{+}$gradient on $\beta$-D-hydroxybutyrate uptake. The effect of variations in the magnitude of the $\mathrm{pH}$ 


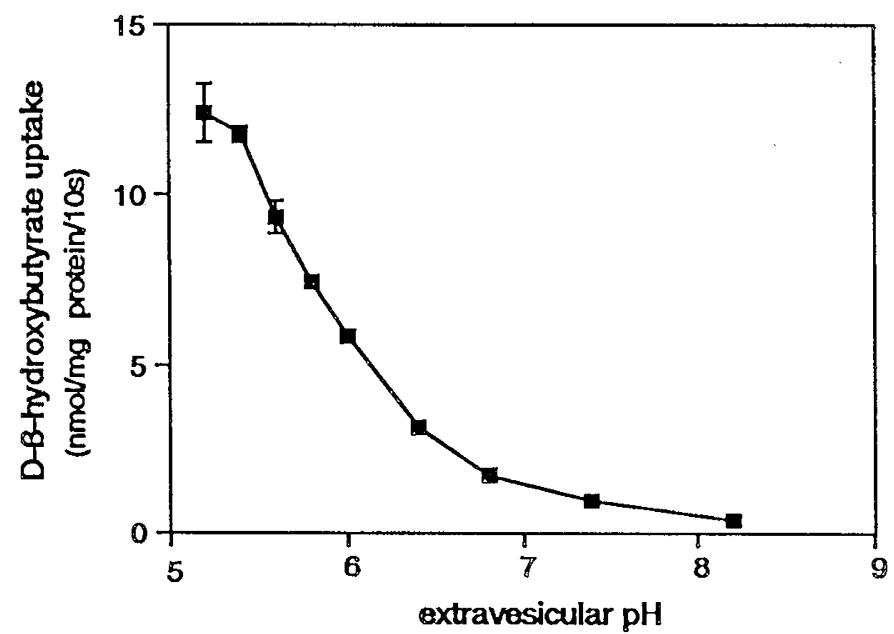

Fig. 1. Effect of extravesicular $\mathrm{pH}$ on $\beta$-D-hydroxybutyrate transport in BBMV from rat placenta. BBMV were preloaded with a buffer containing $500 \mathrm{mM}$ sorbitol, $20 \mathrm{mM}$ Tris/Mes (pH 7.4). Incubation was performed for $10 \mathrm{~s}$ at $37^{\circ} \mathrm{C}$ in a buffer containing $1 \mathrm{mM} \beta$-D- $\left[3-{ }^{14} \mathrm{C}\right]-$ hydroxybutyrate, $599 \mathrm{mM}$ sorbitol, and $20 \mathrm{mM}$ Tris/Mes adjusted to different $\mathrm{pH}$. Each data point represents the mean \pm SEM of four experiments.

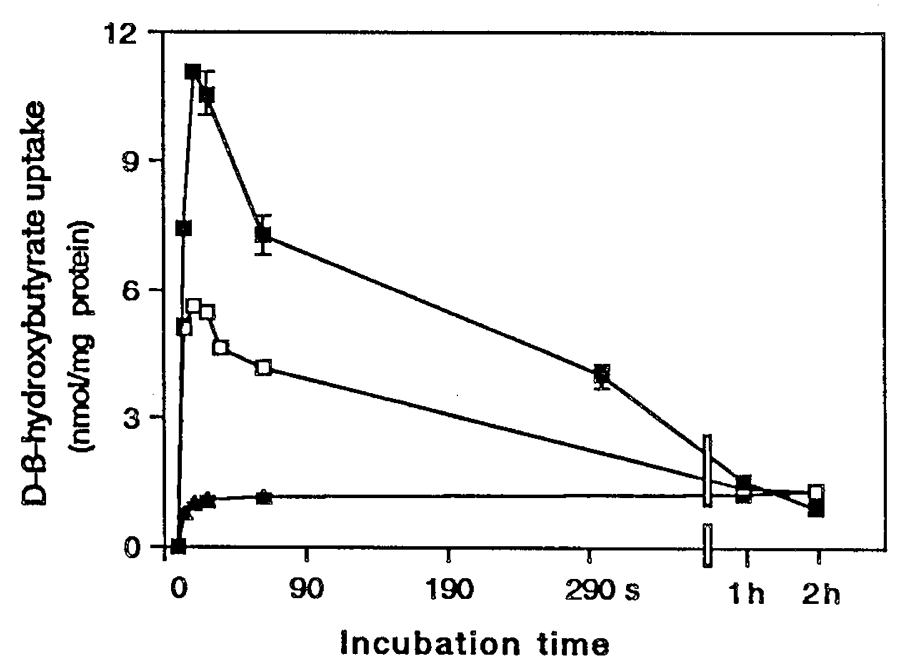

Fig. 2. Effect of increasing inward-directed proton gradients on $\beta$-Dhydroxybutyrate transport in BBMV from rat placenta. BBMV were preloaded with a buffer containing $500 \mathrm{mM}$ sorbitol and $20 \mathrm{mM}$ Tris/ Mes. Incubation was performed at $37^{\circ} \mathrm{C}$ in buffers containing $1 \mathrm{mM} \beta$ $\mathrm{D}-\left[3{ }^{-14} \mathrm{C}\right]$-hydroxybutyrate, $599 \mathrm{mM}$ sorbitol, and $20 \mathrm{mM}$ Tris/Mes; $\mathrm{pHin}=7.4 / \mathrm{pHout}=5.4$, upper curve $; \mathrm{pHin}=7.4 / \mathrm{pHout}=6.0$, middle curve; or $\mathrm{pHin}=6.0 / \mathrm{pHout}=6.0$ and $\mathrm{pHin}=7.4 / \mathrm{pHout}=7.4$, lower curve. Each data point represents the mean \pm SEM of four experiments.

gradient on $\beta$-D-hydroxybutyrate uptake across the BBMV is shown in Figure 2 . These findings show that in the presence of an inward-directed proton gradient $(\mathrm{pHin}=7.4 / \mathrm{pHout}=5.4) 1$ $\mathrm{mM} \beta$-D-hydroxybutyrate uptake was rapid and a transient accumulation "overshoot" was observed, i.e. 10-fold higher uptake at $10 \mathrm{~s}$ than at equilibrium. A lower transmembrane $\mathrm{pH}$ gradient $(\mathrm{pHin}=7.4 / \mathrm{pHout}=6.0)$ was associated with a slow initial uptake rate and with a small transient accumulation (5-fold higher uptake at $10 \mathrm{~s}$ than at the equilibrium). In the absence of an inward-directed proton gradient $(\mathrm{pHin}=7.4 / \mathrm{pHout}=7.4$ or pHin $=6.0 /$ pHout $=6.0$ ), no overshoot was observed (Fig. 2 ). These results lent further support to the notion that $\beta$-D-hydroxybutyrate is taken up in BBMV from rat placenta by a mechanism in which the proton gradient provides the driving force for an uphill accumulation.

Effect of inward-directed $\mathrm{Na}^{+}$gradient. To quantify the contri- bution of an inside-diffusion potential generated by cations on $\beta$-D-hydroxybutyrate uptake across BBMV from rat placenta, we investigated the effect of different magnitudes of an inwarddirected $\mathrm{Na}^{+}$gradient on $1 \mathrm{mM} \beta$-D-hydroxybutyrate uptake in the presence $(\mathrm{pHin}=7.4 / \mathrm{pHout}=6.0)$ or absence $(\mathrm{pHin}=7.4 /$ pHout $=7.4$ ) of a proton gradient. Figure 3 illustrates $\beta$-Dhydroxybutyrate uptake when $\mathrm{Na}^{+}$gradients of different magnitudes, were established. No significant increase in the initial uptake rate was observed either in the presence or in the absence of a proton gradient when inwardly directed $\mathrm{Na}^{+}$gradients of different magnitude were imposed. These results rule out the involvement of an $\mathrm{Na}^{+}$gradient as the driving force of $\beta$-Dhydroxybutyrate uptake in BBMV from rat placenta.

Effect of FCCP on $\beta$-D-hydroxybutyrate uptake. The stimulatory effect of a proton gradient on $\beta$-D-hydroxybutyrate uptake across BBMV could be due to the generation of an inside-positive diffusion membrane potential that would favor the influx of charged $\beta$-D-hydroxybutyrate. To discard such an effect, we investigated the effect of the protonophore FCCP $(100 \mu \mathrm{M})$ on $1 \mathrm{mM} \beta$-D-hydroxybutyrate uptake in the presence and absence of a pH gradient. As shown in Figure $4, \beta$-D-hydroxybutyrate uptake was significantly inhibited by FCCP in the presence of an inward-directed proton gradient but was unaffected in the absence of a proton gradient. This suggests that FCCP did not generate an inside-positive membrane potential, instead, the protonophore would act by dissipating a proton gradient. Consequently, this result is consistent with the idea that an $\mathrm{H}^{+}$ gradient is the driving force of the electroneutral transport of $\beta$ D-hydroxybutyrate in BBMV from rat placenta.

Effect of DIDS and furosemide on $\beta$-D-hydroxybutyrate uptake. To further distinguish whether $\beta$-D-hydroxybutyrate uptake is accomplished in BBMV by a symport mechanism ( $\beta$-D-hydroxybutyrate $\left./ \mathrm{H}^{+}\right)$or by an antiport mechanism $(\beta$-D-hydroxybutyrate $/ \mathrm{OH}^{-}$), we carried out experiments testing the effect of 0.5 mM DIDS or furosemide, specific inhibitors of anion exchangers, on $1 \mathrm{mM} \beta$-D-hydroxybutyrate uptake in the presence of a proton gradient. The data indicated that $\beta$-D-hydroxybutyrate uptake is insensitive to either DIDS or furosemide $(4.28 \pm 0.42$ versus $4.37 \pm 0.04$ or $5.11 \pm 0.23$ versus $4.75 \pm 0.46 \mathrm{nmol} \cdot \mathrm{mg}^{-1} \cdot 10$ $\mathrm{s}^{-1}$ in controls, respectively). These results show that $\beta$-D-hydroxybutyrate transport in BBMV from rat placenta is not achieved by an $\beta$-D-hydroxybutyrate $/ \mathrm{OH}^{-}$antiporter but rather through a

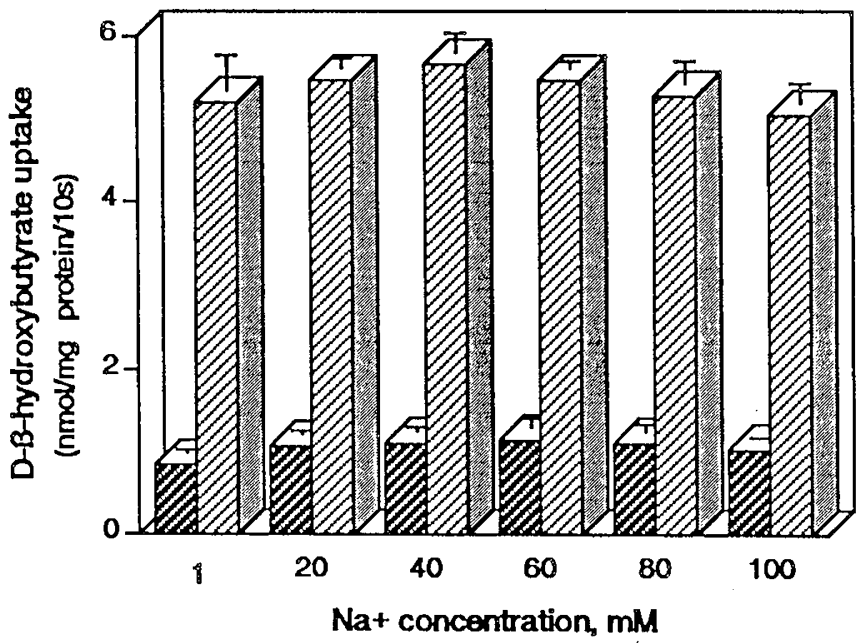

Fig. 3. Effect of cis-Na+ ${ }^{+}$on $\beta$-D-hydroxybutyrate uptake in BBMV from rat placenta. BBMV were preloaded with a buffer containing 500 $\mathrm{mM}$ sorbitol and $20 \mathrm{mM}$ Tris/Mes (pH 7.4). Incubations were performed at $37^{\circ} \mathrm{C}$ in a buffer containing $1 \mathrm{mM} \beta$-D-[3- $\left.{ }^{14} \mathrm{C}\right]$-hydroxybutyrate, enough sorbitol to maintain the osmolarity, and 1 to $100 \mathrm{mM} \mathrm{NaCl}$ and $20 \mathrm{mM}$ Tris/Mes adjusted to $\mathrm{pH} 7.4$ (dark shaded bars) or to $\mathrm{pH} 6.0$ (light shaded bars). Each data point represents the mean \pm SEM of three determinations. 


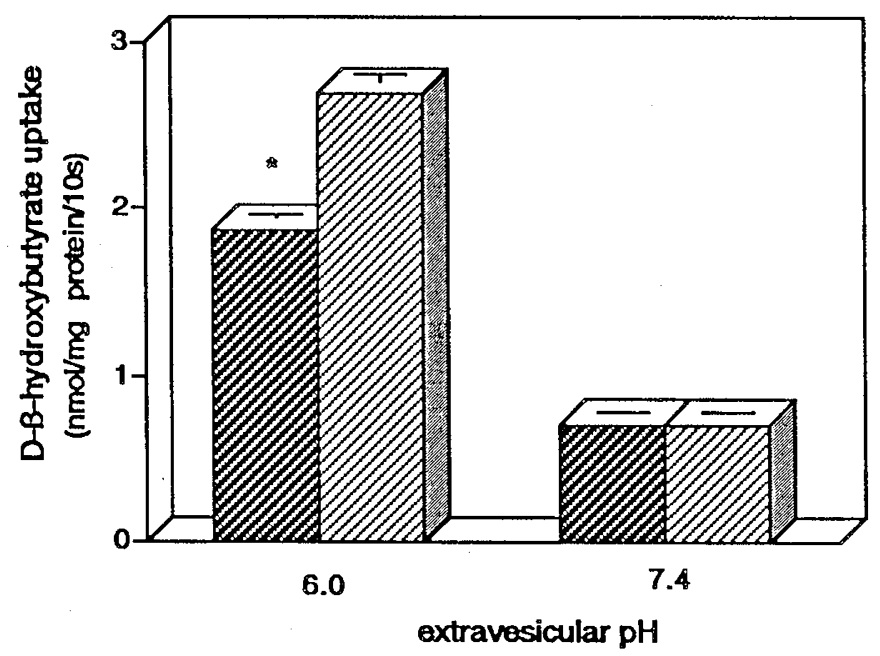

Fig. 4. Effect of FCCP on $\beta$-D-hydroxybutyrate uptake by BBMV from rat placenta. BBMV were preloaded with a buffer containing 500 $\mathrm{mM}$ sorbitol and $20 \mathrm{mM}$ Tris/Mes (pH 7.4). Uptake of $1 \mathrm{mM} \beta$-D-[3${ }^{14} \mathrm{C}$-hydroxybutyrate was measured at $37^{\circ} \mathrm{C}$ for $10 \mathrm{~s}$ in an incubation buffer containing $20 \mathrm{mM}$ Tris/Mes (pH 6.0 or 7.4) and enough sorbitol to maintain the osmolarity in the presence (dark shaded bars) or in the absence (light shaded bars) of $100 \mu \mathrm{M}$ FCCP. Results are means \pm SEM of four experiments.

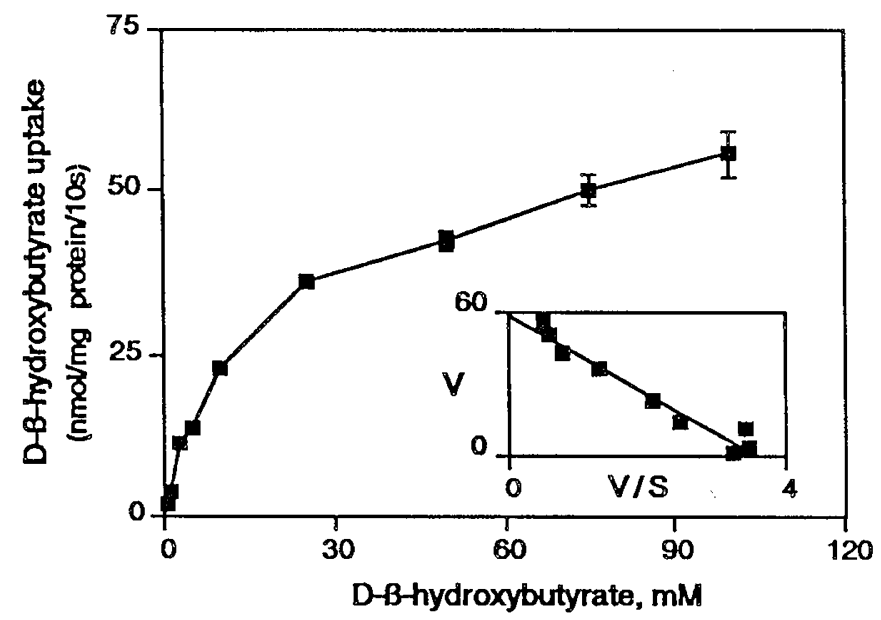

Fig. 5. $\beta$-D-hydroxybutyrate uptake as a function of concentration of $\beta$-D-hydroxybutyrate in BBMV from rat placenta. BBMV were preloaded with a buffer containing $500 \mathrm{mM}$ sorbitol and $20 \mathrm{mM}$ Tris/Mes (pH 7.4). Incubation was performed at $37^{\circ} \mathrm{C}$ for $10 \mathrm{~s}$ in buffers containing increasing concentrations of $\beta$-D-[3- $\left.{ }^{14} \mathrm{C}\right]$-hydroxybutyrate and $20 \mathrm{mM}$ Tris/Mes adjusted to $\mathrm{pH} 6.0$ and enough sorbitol to maintain the osmolarity. Inset, Eadie-Hofstee plot of the data. Results are means \pm SEM of three experiments.

cotransport system coupled to a proton gradient. These findings support the previous observations that the proton gradient is the driving force for an electroneutral $\beta$-D-hydroxybutyrate $/ \mathrm{H}^{+}$symport.

Kinetics of $\beta$-D-hydroxybutyrate uptake. The concentration dependence of $\beta$-D-hydroxybutyrate was examined at $37^{\circ} \mathrm{C}$ for $10 \mathrm{~s}$ in the presence of an inward-directed proton gradient (pHin $=7.4 / \mathrm{pHout}=6.0$ ). Figure 5 shows that $\beta$-D-hydroxybutyrate uptake is saturable at high concentrations of substrate. Total uptake rates were fitted by nonlinear regression to an equation with two terms, one saturable and one nonsaturable (diffusion): $\mathrm{v}=\left(\mathrm{V}_{\max }[\mathrm{S}] / \mathrm{Km}+[\mathrm{S}]\right)+\mathrm{k}_{\mathrm{d}}[\mathrm{S}]$ in which $\mathrm{v}$ is actual velocity and [S] is substrate concentration. The values of $\mathrm{Km}, \mathrm{V}_{\max }$, and $\mathrm{k}_{\delta}$ calculated by applying the iteration procedure to the data were $16 \mathrm{mM}, 58 \mathrm{nmol} \cdot \mathrm{mg}^{-1} \cdot 10 \mathrm{~s}^{-1}$, and $0 \mathrm{~nL} \cdot \mathrm{mg}^{-1} \cdot \mathrm{s}^{-1}$, respectively.
The inset shows Eadie-Hofstee analysis of the experimental data represented in Figure 5. The linear plot obtained confirms the involvement of only one transport system for $\beta$-D-hydroxybutyrate uptake in BBMV from rat placenta. From these results, it may be inferred that $\beta$-D-hydroxybutyrate uptake in BBMV is accomplished by a transport system with very low affinity.

Trans-stimulation of $\beta-D$-hydroxybutyrate uptake. One $\mathrm{mM} \beta-$ D-hydroxybutyrate uptake was studied at $37^{\circ} \mathrm{C}$ for $10 \mathrm{~s}$ in BBMV preloaded with $10 \mathrm{mM} \beta$-D-hydroxybutyrate, L-lactate, or pyruvate either in the presence $(\mathrm{pHin}=7.4 / \mathrm{pHout}=6.0$ ) or absence $(\mathrm{pHin}=7.4 / \mathrm{pHout}=7.4$ ) of an inward-directed proton gradient. The monocarboxylic acids inside vesicles significantly stimulated $\beta$-D-hydroxybutyrate uptake both in the presence and absence of a proton gradient (Table 1). Taken together, these results might suggest the existence of a general monocarboxylic acid transport system with exchange properties in BBMV from trophoblast rat placenta.

Inhibition of $\beta$-D-hydroxybutyrate uptake by other monocarboxylic acids. To characterize the stereospecificity of the $\beta$-Dhydroxybutyrate transport system, we examined the inhibitory effect of several monocarboxylic acids, namely $\beta$-D-hydroxybutyrate $\beta$-L-hydroxybutyrate, L-lactate, and pyruvate on $1 \mathrm{mM} \beta$ D-hydroxybutyrate uptake at $37^{\circ} \mathrm{C}$ for $10 \mathrm{~s}$ (Table 2 ). The presence of these monocarboxylic acids on the cis side of the membrane strongly inhibits $\beta$-D-hydroxybutyrate uptake. These results reinforced the suggestion of the existence of a common carrier for monocarboxylic acids in BBMV from rat placenta trophoblast. The observed inhibition of $\beta$-D-hydroxybutyrate uptake by $\beta$-L-hydroxybutyrate points to the low stereospecificity of the carrier.

Effect of gestational age on $\beta$-D-hydroxybutyrate transport system. The concentration dependence of $\beta$-D-hydroxybutyrate uptake in BBMV from trophoblast rat placenta at 19.5, 20.5, and $21.5 \mathrm{~d}$ of gestation is shown in Figure 6 . These results show that during the last $3 \mathrm{~d}$ of gestation there were no changes in the kinetic parameters of the $\beta$-D-hydroxybutyrate transport system due to development (Table 3).

Table 1. Trans-stimulation of $\beta$-D-hydroxybutyrate uptake by preloading vesicles with unlabeled L-lactate, pyruvate, or $\beta$ hydroxybutyrate*

\begin{tabular}{lcccc}
\hline & $\mathrm{pH} 6.0$ & $\%$ & $\mathrm{pH} 7.4$ & $\%$ \\
\hline Control & $5.22 \pm 0.13$ & & $0.89 \pm 0.03$ & \\
$10 \mathrm{mM} \beta-\mathrm{HB}$ & $6.94 \pm 0.02$ & 133 & $1.20 \pm 0.04$ & 135 \\
$10 \mathrm{mM} \mathrm{pyr}$ & $7.57 \pm 0.05$ & 145 & $1.57 \pm 0.01$ & 176 \\
$10 \mathrm{mM} \mathrm{lac}$ & $6.95 \pm 0.02$ & 133 & $1.33 \pm 0.05$ & 150 \\
\hline
\end{tabular}

* BBMV were preloaded with and without (control) $10 \mathrm{mM}$ unlabeled $\beta$-D-hydroxybutyrate $(\beta-\mathrm{HB})$, L-lactate (lac), or pyruvate (pyr) at $\mathrm{pH}$ 7.4. Uptake rates of $1 \mathrm{mM} \beta$-D-hydroxybutyrate were measured at $37^{\circ} \mathrm{C}$ for $10 \mathrm{~s}$ at the $\mathrm{pH}$ indicated. $\beta$-D-Hydroxybutyrate uptakes are expressed in $\mathrm{nmol} / \mathrm{mg}$ protein $/ 10 \mathrm{~s}$ and are means \pm SEM of at least four experiments. Percentages were calculated taking each corresponding control as $100 \%$.

Table 2. Inhibitory effect of monocarboxylates on $\beta$-Dhydroxybutyrate uptake by BBMV from rat placenta*

\begin{tabular}{lc}
\hline \multicolumn{1}{c}{ Inhibitor } & $\begin{array}{c}\text { Relative uptake } \\
\text { (\% of control) }\end{array}$ \\
\hline None & 100 \\
$10 \mathrm{mM} \beta$-D-hydroxybutyrate & $53.0 \pm 0.5$ \\
$10 \mathrm{mM} \beta$-L-hydroxybutyrate & $54.0 \pm 2.9$ \\
$10 \mathrm{mM}$ L-lactate & $45.0 \pm 7.5$ \\
$10 \mathrm{mM}$ pyruvate & $45.0 \pm 0.5$
\end{tabular}

* Membrane vesicles were preloaded with $500 \mathrm{mM}$ sorbitol and 20 $\mathrm{mM}$ Tris/Mes buffer (pH 7.4). Uptake of $1 \mathrm{mM} \beta$-D-hydroxybutyrate was measured at $37^{\circ} \mathrm{C}$ for $10 \mathrm{~s}$ by incubating the membrane vesicles in $20 \mathrm{mM}$ Tris/Mes buffer ( $\mathrm{pH} 6.0$ ) containing $10 \mathrm{mM}$ of inhibitors. Enough sorbitol was added to maintain the osmolarity. Each value represents the mean \pm SEM of three to five experiments. 
A
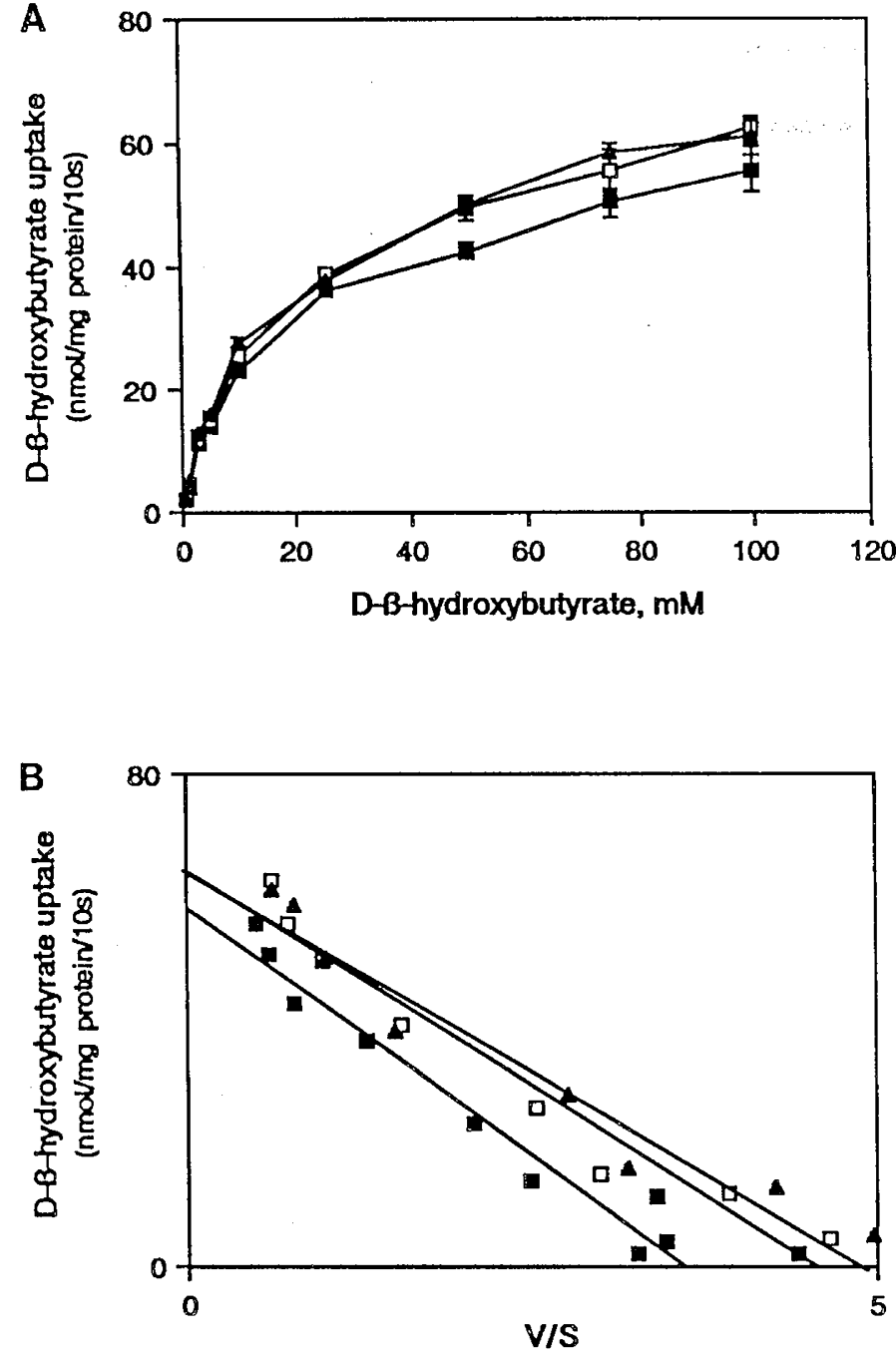

Fig. 6. $\beta$-D-hydroxybutyrate uptake as a function of concentration of $\beta$-D-hydroxybutyrate in BBMV from rat placenta during the last $3 \mathrm{~d}$ of gestation. A, BBMV from 19.5 (closed triangles), 20.5 (open squares), and 21.5 (closed squares) d of gestation were preloaded with a buffer containing $500 \mathrm{mM}$ sorbitol and $20 \mathrm{mM}$ Tris/Mes (pH 7.4). Incubation was performed at $37^{\circ} \mathrm{C}$ for $10 \mathrm{~s}$ in buffer containing increasing concentrations of $\beta$-D- $\left[3-{ }^{14} \mathrm{C}\right]$-hydroxybutyrate and $20 \mathrm{mM}$ Tris/Mes adjusted to $\mathrm{pH} 6.0$ and enough sorbitol to maintain the osmolarity. $B$, EadieHofstee plot of the data: $19.5 \mathrm{~d}$, closed triangles; $20.5 \mathrm{~d}$, open squares; and $21.5 \mathrm{~d}$, closed squares. Results are means \pm SEM of three to four experiments. $V / S$, velocity/substrate concentration.

Effect of maternal fasting on $\beta$-D-hydroxybutyrate uptake. Because the placenta plays a regulatory role in the maternofetal transfer of substrates, we investigated the effect of maternal fasting ( $48 \mathrm{~h}$ ) on the kinetic parameters of $\beta$-D-hydroxybutyrate carrier in BBMV from trophoblast rat placenta. The concentration dependence plot of $\beta$-D-hydroxybutyrate uptake in BBMV prepared from placenta of 48 -h fasted rats (Fig. 7) shows a significant increase in $\mathrm{V}_{\max }$ (Table 3 ) as compared with that from unstarved mothers. These results show that the capacity of $\beta$-Dhydroxybutyrate carrier increases as a consequence of maternal starvation without changes in its affinity:

\section{DISCUSSION}

The sensitivity of $\beta$-D-hydroxybutyrate uptake to SH-protein reagents suggests that the transport of $\beta$-D-hydroxybutyrate through brush-border membrane of rat placenta is mediated by a protein $(25-28)$ that collaborates in the translocation of $\beta$-Dhydroxybutyrate through the membrane of the maternal side of
Table 3. Kinetic parameters for $\beta$-hydroxybutyrate uptake in placental microvillous membrane vesicles from fed and starved rats during last $3 d$ of gestation*

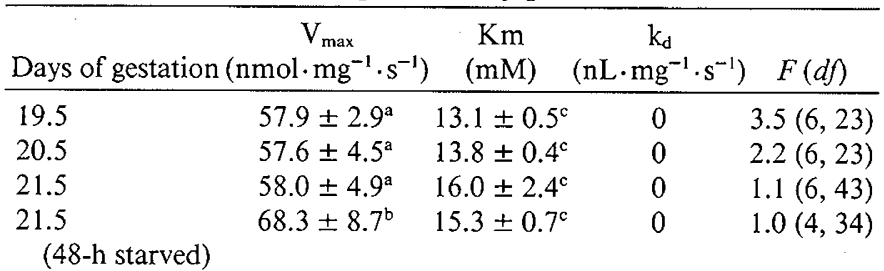

* BBMV from rat placenta prepared at $19.5,20.5$, and $21.5 \mathrm{~d}$ of gestation and from 48 -h starved rats at $21.5 \mathrm{~d}$ of gestation were preloaded with a buffer containing $500 \mathrm{mM}$ sorbitol and $20 \mathrm{mM}$ Tris/Mes (pH 7.4). Incubations were performed at $37^{\circ} \mathrm{C}$ at initial velocities in buffers adjusted at pH 6.0 containing $20 \mathrm{mM}$ Tris/Mes, increasing concentrations of $\beta$-hydroxybutyrate, and enough sorbitol to maintain the osmolarity. Uptake rate data were fitted by nonlinear regression analysis to an equation involving one saturable component and one nonsaturable component. The $F$ test includes the degrees of freedom in parentheses. Results are means \pm SEM. Identical lowercase letters identify results that are indistinguishable from $21.5-\mathrm{d}$ values according to $t$ test. Different lowercase letters mean $p<0.05$.

the placenta. The transport of $\beta$-D-hydroxybutyrate is not dependent on an $\mathrm{Na}^{+}$gradient (Fig. 3) but rather is driven by an inwardly directed proton gradient (Figs. 1 and 2 ). The possibility of a proton gradient being the driving force for $\beta$-D-hydroxybutyrate transport was reinforced by the fact that dissipation of the proton gradient by the presence of FCCP (Fig. 4) inhibited $\beta$-Dhydroxybutyrate transport. In addition, the inhibition caused by FCCP (Fig. 4) but not by DIDS or furosemide suggests that $\beta$-Dhydroxybutyrate is transported by a $\beta$-D-hydroxybutyrate $/ \mathrm{H}^{+}$ symport mechanism rather than by a $\beta$-D-hydroxybutyrate $/ \mathrm{OH}^{-}$ antiporter. A similar proton-coupled mechanism for $\beta$-D-hydroxybutyrate transport has been described in thymocytes, erythrocytes, and dissociated cells from rat brain $(12,28)$.

Nonlinear regression analysis of the concentration-dependent kinetics of $\beta$-D-hydroxybutyrate uptake shows that the diffusional component of the passage of $\beta$-D-hydroxybutyrate through the maternal-sided placental membrane is negligible, suggesting that most $\beta$-D-hydroxybutyrate uptake is carried out by a mediated mechanism. Moreover, the linearity of the Eadie-Hofstee (Fig. 5 ) plot suggests that carrier-mediated $\beta$-D-hydroxybutyrate transport through BBMV is accomplished by a single mechanism. The $\mathrm{Km}$ value observed in our experiments is similar to that found in erythrocytes (12) and blood-brain barrier (11) but higher than that found in dissociated brain cells (28). Ketone body concentrations in maternal blood $(13,30,31)$ are much lower than the $\mathrm{Km}$ observed in our experiments, suggesting that $\beta$-Dhydroxybutyrate transport through BBMV is permanently dependent on its maternal concentration. This low-affinity mechanism would prevent saturation of the carrier at physiologic concentrations of ketone bodies. This may be the case in maternal starvation, in which the $V_{\max }$ of the carrier increases without changes in $\mathrm{Km}$ (Fig. 7). These changes coincide with the enhancement of plasma concentrations of ketone bodies in the mother $(13,30,31)$. This may provide ketone bodies to the fetus as an alternative fuel to glucose during maternal starvation, in fact, during late gestation fetal ketogenesis is not induced (4), which is consistent with the idea that ketone bodies are supplied by the mother to the fetus to continue its development even though the glucose supply is restricted. It should be mentioned that ketone bodies are synthesized by the mother from her own reserves, allowing a supply of metabolic fuels to the fetus without relying on exogenous nutrients. it is not surprising that during the suckling period, when the blood-brain barrier finally substitutes the placenta in the control of selective substrate supply to the brain, $\beta$-D-hydroxybutyrate transport through the bloodbrain barrier is also stimulated by starvation $(32,33)$. 

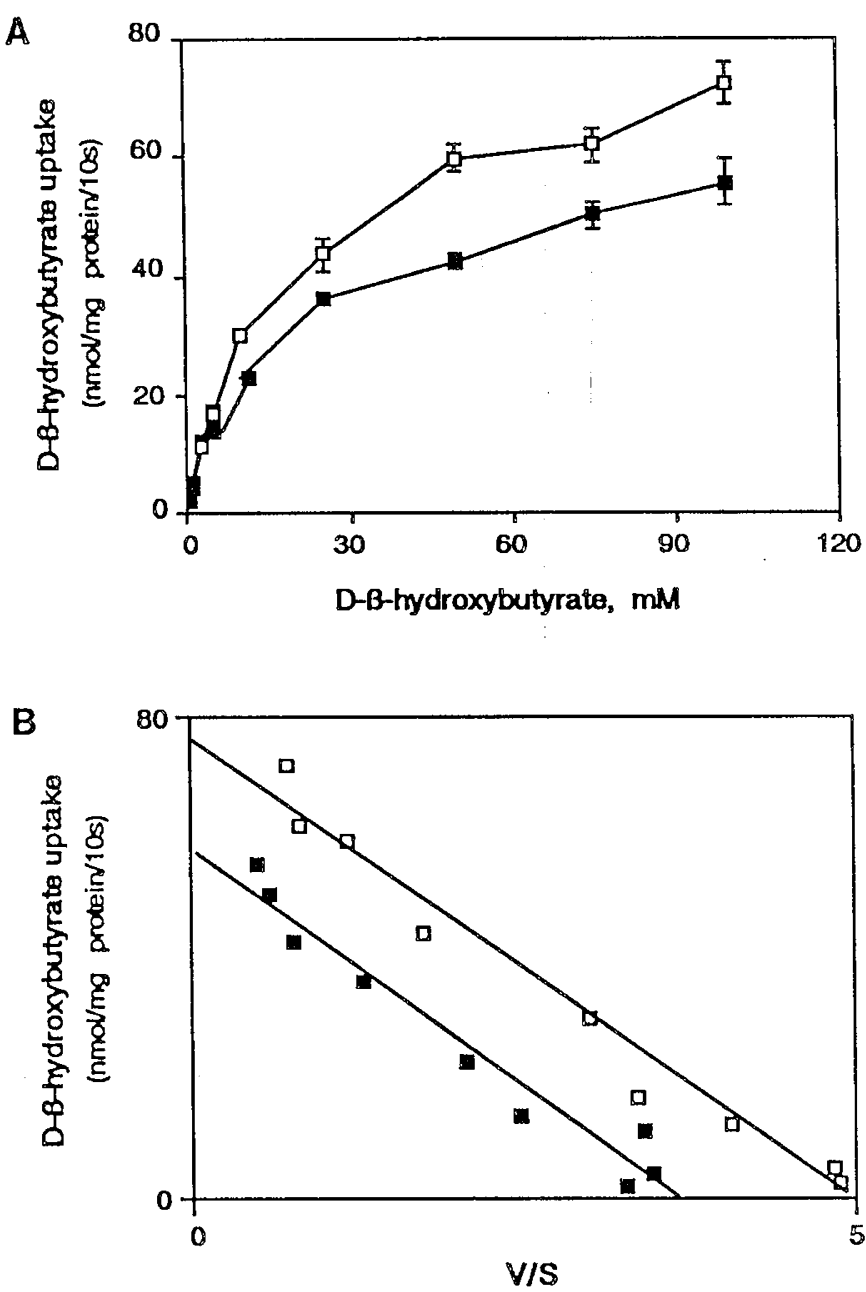

Fig. 7. $\beta$-D-hydroxybutyrate uptake as a function of concentration of $\beta$-D-hydroxybutyrate in BBMV of rat placenta from fed and fasted mothers. A, BBMV from fed (closed squares) and 48-h fasted (open squares) pregnant rats at term of gestation were preloaded with a buffer containing $500 \mathrm{mM}$ sorbitol and $20 \mathrm{mM}$ Tris/Mes (pH 7.4). Incubation was performed at $37^{\circ} \mathrm{C}$ for $10 \mathrm{~s}$ in buffers containing increasing concentrations of $\beta$-D-[3- $\left.{ }^{14} \mathrm{C}\right]$-hydroxybutyrate and $20 \mathrm{mM}$ Tris/Mes adjusted to $\mathrm{pH} 6.0$ and enough sorbitol to maintain the osmolarity. $B$, EadieHofstee plot of the data: fed, closed squares; and fasted, open squares. Results are means \pm SEM of three to four experiments. $V / S$, velocity/ substrate concentration.

However, the low specificity of the carrier (Table 2) together with its possible reversibility (Table 1 ) suggest that $\beta$-D-hydroxybutyrate shares a common carrier-mediated mechanism with other monocarboxylic acids. In this sense, kinetic parameters similar to those of the $\beta$-D-hydroxybutyrate carrier (Table 3 ) have been reported for lactate transport across human $(34,35)$ and rat (14) placental membranes, a fact consistent with the idea that a common carrier may be responsible for the transport of monocarboxylic acid across placental membranes. This may explain our results, in which the kinetic parameters of the carrier did not change during late gestation (Fig. 6) because a carrier used by different monocarboxylates would not be expected to be sensitive to development; if this were so, it would not be able to fulfill the requirements of each particular substrate. Nevertheless, ketone bodies may be the major substrates transported by this carrier because of the importance of these substrates in fetal development, particularly during maternal fasting. In fact, maternal blood ketone body concentrations increased 100-fold because of starvation, whereas the concentrations of other putative substrates of this carrier, such as lactate or pyruvate, were maintained in these circumstances (31). Whether the increase in ketone body transport through placental membranes caused by starvation is associated with concurrent enhancement of maternal ketogenesis by a common signal for both processes remains to be elucidated.

Acknowledgment. The authors thank Nicholas Skinner for revising the manuscript and Juan Villoria for technical assistance.

\section{REFERENCES}

1. Seccombe DW, Harding PGR, Possmayer F 1977 Fetal utilization of maternally derived ketone bodies for lipogenesis in the rat. Biochim Biophys Acta 448:402-416

2. Zolnierowicz S, Scislowski J, Swierczynski J, Zelewski L 1984 Acetoacetate utilization by human placental mitochondria. Placenta 5:271-276

3. Shambaugh GE 1985 Ketone body metabolism in the mother and fetus. Fed Proc 44:2347-2351

4. Ferré P, Satabin P, Decaux JF, Escrivá F, Girard J 1983 Development and regulation of ketogenesis in hepatocytes isolated from newborn rats. Biochem J 214:937-942

5. Leturque A, Hauguel S, Kande J, Girard J 1987 Glucose utilization by the placenta of anesthetized rats: effect of insulin, glucose, and ketone bodies. Pediatr Res 22:483-487

6. Medina JM, Fernández E, Bolaños JP, Vicario C, Arizmendi C 1990 Fuel supply to the brain during the early postnatal period. In: Cuezva JM, PascualLeone MA, Patel M (eds) Endocrine and Biochemical Development of the Fetus and Neonate. Plenum Press, New York, pp 175-194

7. Vicario C, Arizmendi C, Medina JM 1990 Utilization of the main metabolic substrates by freshly isolated cells from the fetal rat brain. In: Cuezva JM, Pascual-Leone AM, Patel M (eds) Endocrine and Biochemical Development of the Fetus and Neonate. Plenum Press, New York, pp 195-201

8. Paterson P, Sheath J, Taft P, Wood C 1967 Maternal and fetal ketone concentrations in plasma and urine. Lancet 22:862-865

9. Metcalfe HK, Monson JP, Welch SG, Cohen RD 1986 Carrier-mediated efflux of ketone bodies in isolated rat hepatocytes. Clin Sci 71:755-761

10. Jorgensen KE, Sheikh MI 1985 Mechanisms of uptake of ketone bodies by luminal membrane vesicles. Biochim Biophys Acta 814:23-34

11. Conn AR, Fell DL, Steele RD 1983 Characterization of $\alpha$-keto acid transport across blood-brain barrier in rats. Am J Physiol 245:E253-E260

12. Regen DM, Tarpley HL 1978 Effects of $\mathrm{pH}$ on $\beta$-hydroxybutyrate transport in rat erythrocytes and thymocytes. Biochim Biophys Acta 508:539-550

13. López-Soriano FJ, Argilés JM 1986 Rat acetoacetate decarboxylase: its role in the disposal of 4-C ketone bodies by the fetus. Horm Metab Res 18:446449

14. Alonso de la Torre SR, Serrano MA, Alvarado F, Medina JM 1991 Carriermediated L-lactate transport in brush-border membrane vesicles from rat placenta during late gestation. Biochem J 278:535-541

15. Smith CH, Nelson D, King B, Donohue T, Ruzycki S, Kelley L 1977 Characterization of a microvillous membrane preparation from human placental syncytiotrophoblast: a morphologic, biochemical and physiologic study. Am J Obstet Gynecol 128:190-196

16. Garcia Marin JJ, Dumont M, Corbic M, de Couet G, Erlinger S 1985 Effect of acid-base balance and acetazolamide on ursodeoxycholate-induced biliary bicarbonate secretion. Am J Physiol 248:G20-G27

17. Glazier JD, Jones CJP, Sibley CP 1990 Preparation of plasma membrane vesicles from rat placenta at term and measurements of $\mathrm{Na}^{+}$uptake. Placenta $11: 451-463$

18. Bretaudiere JP, Spillman T 1984 Alkaline phosphatases. Orthophosphoric monoester phosphohydrolase (alkaline optimum). In: Bergmeyer $\mathrm{HU}$ (ed) Methods of Enzymatic Analysis. Verlag Chemie GmbH, Weinheim, Germany, pp 75-83

19. Scharschmidt BF, Keefe EB, Blankenship NM, Ockner RK 1979 Validation and recording spectrophotometric method for measurement of membrane associated $\mathrm{Mg}^{2+}$ and $\mathrm{Na}^{+} / \mathrm{K}^{+}$ATPase activity. J Lab Clin Med 93:790-799

20. Markwell MAK, Haas SM, Bieber LL, Tolbert NE 1978 A modification of the Lowry procedure to simplify protein determination in membrane and lipoprotein samples. Anal Biochem 87:206-210

21. Hopfer U, Nelson K, Perrotto J, Isselbacher KJ 1973 Glucose transport in isolated brush-border membrane from rat small intestine. $J$ Biol Chem 248:25-32

22. Van Melle G, Robinson JWL 1981 A systematic approach to the analysis of intestinal transport kinetics. J Physiol (Paris), 77:1011-1016

23. Robinson JWL, Van Melle G 1983 Kinetics of the sodium $\beta$-methyl-Dglucoside cotransport system in guinea pig small intestine. J Physiol (Lond) 344:177-187

24. Brot-Laroche E, Serrano MA, Delhomme B, Alvarado F 1986 Temperature sensitivity and substrate specificity of two distinct $\mathrm{Na}^{+}$-activated $\mathrm{D}$-glucose transport systems in guinea-pig jejunal brush border membrane vesicles. $J$ Biol Chem 261:6168-6176

25. Spencer TL, Lehninger AL 1976 L-Lactate transport in Ehrlich ascites-tumour cells. Biochem J 154:405-414

26. Deuticke B, Rickert I, Beyer E 1978 Stereoselective, SH-dependent transfer of lactate in mammalian erythrocytes. Biochim Biophys Acta 507:137-155

27. Juel C, Wilbrand F 1989 Lactate transport in isolated mouse muscles studied with a tracer technique: kinetics, stereospecificity, pH dependency and maximal capacity. Acta Physiol Scand 137:33-39 
28. Tildon JT, Roeder LM 1988 Transport of 3-hydroxy $\left[3-{ }^{14} \mathrm{C}\right]$ butyrate by dissociated cells from rat brain. Am J Physiol 255:C133-C139

29. Trosper TL, Phillpson KD 1987 Lactate transport by cardiac sarcolemmal vesicles. Am J Physiol 252:C483-C489

30. Herrera E, Gómez-Coronado D, Lasunción MA 1987 Lipid metabolism in pregnancy. Biol Neonate 51:70-77

31. Girard JR, Ferré P, Gilbert M, Kevran A, Assan R, Marliss B 1977 Fetal metabolic response to maternal fasting in the rat. Am J Physiol 232:E456E463

32. Moore TJ, Lione AP, Sugden MC, Regen DM $1976 \beta$-Hydroxybutyrate transport in rat brain: developmental and dietary modulations. Am J Physiol 230:619-630

33. Gjedde A, Crone C 1975 Induction processes in blood-brain transfer of ketone bodies during starvation. Am J Physiol 229:1165-1169

34. Balkovetz DF, Leibach FH, Mahesh VB, Ganapathy VA 1988 A protongradient is a driving force for uphill transport of $\mathrm{L}$-lactate in human placental brush border membrane vesicles. J Biol Chem 263:13823-13830

35. Alonso de la Torre SR, Serrano MA, Caro-Patón T, Medina JM 1991 Proton gradient-dependent active transport of L-lactate in basal plasma membrane vesicles isolated from syncytiotrophoblast human placenta. Biochem Soc Trans 19:409s-410s

\section{Announcement}

\section{Nomination for Awards}

The American Society for Clinical Nutrition is pleased to invite nominations for awards of the society. Nominees need not be members of the society and nominations may be made by anyone. Nomination forms are available from the ASCN Secretariat, 9650 Rockville Pike, Bethesda, MD 20814. Telephone (301) 530-7110.

The McCollum Award is given to a clinical investigator generally perceived as currently a major creative force, actively generating new concepts in nutrition and personally seeing to the execution of studies testing the validity of these concepts. A cash award and inscribed plaque are provided by the National Dairy Council.

The Robert H. Herman Memorial Award in Clinical Nutrition is given to a clinical investigator whose research work has contributed importantly to the advancement of clinical nutrition in areas particularly involving the biochemical and metabolic aspects of human nutrition. A cash award and inscribed plaque are provided by the Robert H. Herman Memorial Fund established by the society and Mrs. Yaye Tokuyama Herman.

The National Dairy Council Award for Excellence in Medical/Dental Nutrition Education is presented in recognition of an outstanding career in medical and/or dental nutrition education. The results of the nominee's efforts should be widely recognized and have had a national or international impact. Nomination will depend on acknowledged excellence in nutrition teaching or nutrition education research that extends beyond the local institution and that includes innovations in medical/dental nutrition education. A cash award and inscribed plaque are provided by the National Dairy Council.

Deadline for receipt of nominations to be awarded in 1993 is November 20, 1992. 